Jurnal Ekonomi dan Industri

Volume 20, No. 1, Januari-April 2019

p-ISSN : 0853-5248

\title{
PENGARUH KOMPENTENSI DAN KOMPENSASI TERHADAP KINERJA KARYAWAN PT. MEDIA NUSANTARA CITRA TBK
}

\author{
Hery Wihasnanto *) \\ *) Dosen Program Studi Manajemen FE UNKRIS \\ Alamat: Kampus UNKRIS, Jatiwaringin Jakarta Timur \\ Email : herywihasnanto@unkris.ac.id / hkhery86@gmail.com
}

\begin{abstract}
This research is aims to determine the effect of competency and compensation on employee performance, the effect of compensation on employee performance taking this sample using the simple random sampling method. The data is then analyzed using regression, based on data analysis, it is known that the competency and compensation variables have a significant effect on employee performance. This means that competence and compensation affect employee performance simultaneously. Partially competency variables affect significant employee performance. This means that the competency variables have a significant effect on employee performance. The compensation variable partially affects significant employee performance.
\end{abstract}

Keywords: Competence, compensation, employee performance

\section{PENDAHULUAN}

Dalam menghadapi era globalisasi dan kemajuan teknologi, peran serta sumber daya manusia (SDM) dalam suatu organisasi itu sangat penting dalam periode waktu tertentu, oleh karena itu di butuhkan peran serta sumber daya manusia yang handal . dengan begitu kunci pokok penentu keberhasilan pelaksanaan kegiatan perusahaan dapat berjalan dengan baik untuk mencapai tujuan perusahaan. Berdasarkan hasil observasi dan wawancara dengan pihak HRD PT. Media Nusantara Citra Tbk, diperoleh informasi bahwa faktor penyebabnya antara lain disebabkan oleh beberapa hal. Pertama, Sikap kompetensi belum dijalankan secara optimal sehingga berdampak pada tingkat kinerja dalam melakukan pekerjaannya, Kedua Kompensasi kerja yang tidak dikelola dengan efektif yang menimbulkan masalah dalam peningkatan kinerja karyawan.

Selain keterbatasan yang disebabkan oleh dua faktor diatas, kendala lain yang dihadapi PT. Media Nusantara Citra Tbk. Adalah minimnya sumber daya manusia yang berkualitas tinggi dalam menyesuaikan gerak terhadap perubahan iklim usaha yang begitu sangat cepat.

Berdasarkan uraian diatas maka peneliti tertarik untuk melakukan penelitian dengan judul Pengaruh Kompentensi dan Kompensasi Terhadap Kinerja Karyawan PT. Media Nusantara Citra. Tbk.

\section{LANDASAN TEORI}

\section{Kompentensi}

Johnson dalam (Syamsuddin 1999), kompetensi adalah suatu penampilan hasil kerja spesifik yang bersifat rasional sebagai harmoni dan jalinan dari pengetahuan, keterampilan, dan kemapuan yang dibutuhkan oleh tugas pekerjaan untuk mencapai 
tujuan-tujuan yang telah ditetapkan dengan penuh keberhasilan. Dimensi Kompetensi terdiri atas : "latar belakang pendidikan, visi dan misi,otodidak,memiliki keterampilan teknis,cepat beradaptasi dengan yang lain"(syamsuddin, 1999).

\section{Kompensasi}

Kompensasi adalah "segala sesuatu yang diterima oleh karyawan sebagai balas jasa untuk kerja atau pengabdian mereka . dalam suatu organisasi masalah kompensasi merupakan masalah komplek, namun paling penting bagi karyawan maupun bagi organisasi itu sendiri" (Notoatmodjo, 2009). Dimensi Kompensasi menurut Notoatmodjo, 2009 terdiri atas : "organisasi administrasi pemberian kompensasi, metode pemberian kompensasi, struktur kompensasi, perangsang kerja, tambahan sumber, terjamin sumber pendapatan, kompensasi bagi kelompok manajerial, prospek di masa depan"

\section{Kinerja Karyawan}

Kinerja karyawan merupakan hasil atau prestasi kerja karyawan yang dinilai dari segi kualitas maupun kuantitas berdasarkan standar kerja yang ditentukan pihak organisasi (Setiyawan dan Waridin, 2006 ).Dimensi Kinerja Karyawan menurut Setiyaawan dan Waridin, 2006 terdiri atas : quantity of work, quality of work, job knowledge, creativeness, cooperation, dependability, initiative, karyawan qualities.

\section{METODE PENELITIAN}

Menurut Jogiyanto (2009), explanatory research merupakan penelitian yang bertujuan untuk menjelaskan fenomena yang ada. Penelitian ini juga memiliki fungsi untuk menguji hipotesis yang telah ada. Hasil dari penelitian ini menjelaskan hubungan kausal antar variabel melalui pengujian hipotesis.

Populasi adalah wilayah generasi yang terdiri atas obyek / subyek yang mempunyai kuantitas dan karakteristik tertentu yang ditetapkan oleh peneliti untuk dipelajari kemudian ditarik kesimpulan nya (Sugiyono, 2005), Sampel adalah penarik sebagian dari populasi untuk mewakili seluruh populasi, (Surakhmad, 1990). Penelitian ini dilakukan di PT. Media Nusantara Citra Tbk. Jumlah seluruh karyawan sebanyak 98 orang pada Bagian Penyiaran. Teknik pengambilan sampel ini disebut juga dengan metode pengambilan sampel jenuh dalam metode pengambilan sampel ini populasi seluruhnya dilibatkan dalam pengambilan sampel. Teknik analisis data menggunakan analisa regresi linier berganda.

\section{HASIL PENELITIAN DAN PEMBAHASAN}

\section{Uji Validitas dan Reliabilitas}

Uji Validitas dan reliabilitas kompetensi, kompensasi dan kinerja karyawan menunjukkan hasil yang valid dan reliabel.

Uji validitas dapat dilihat pada tabel 1 di bawah ini

Tabel 1 Rekapitulasi Hasil Uji Validitas

\begin{tabular}{ccccc}
\hline Keterangan & Kuesioner & R hitung & R kritis & Kesimpulan \\
\hline \multirow{5}{*}{ Kompetensi } & Instrumen No.1 & 0.609 & 0.30 & Valid \\
& Instrumen No.2 & 0.546 & 0.30 & Valid \\
& Instrumen No.3 & 0.591 & 0.30 & Valid \\
& Instrumen No.4 & 0.573 & 0.30 & Valid \\
& Instrumen No.5 & 0.612 & 0.30 & Valid \\
\hline
\end{tabular}




\begin{tabular}{ccccc}
\hline & Instrumen No.6 & 0.630 & 0.30 & Valid \\
& Instrumen No.7 & 0.635 & 0.30 & Valid \\
& Instrumen No.8 & 0.620 & 0.30 & Valid \\
& Instrumen No.9 & 0.542 & 0.30 & Valid \\
& Instrumen No.10 & 0.595 & 0.30 & Valid \\
& Instrumen No.1 & 0.576 & 0.30 & Valid \\
\hline \multirow{5}{*}{ Kompensasi } & Instrumen No.1 & 0.484 & 0.30 & Valid \\
& Instrumen No.2 & 0.302 & 0.30 & Valid \\
& Instrumen No.3 & 0.365 & 0.30 & Valid \\
& Instrumen No.4 & 0.429 & 0.30 & Valid \\
& Instrumen No.5 & 0.481 & 0.30 & Valid \\
& Instrumen No.6 & 0.381 & 0.30 & Valid \\
\hline & Instrumen No.1 & 0.325 & 0.30 & Valid \\
& Instrumen No.2 & 0.576 & 0.30 & Valid \\
& Instrumen No.3 & 0.403 & 0.30 & Valid \\
& Instrumen No.4 & 0.492 & 0.30 & Valid \\
& Instrumen No.5 & 0.545 & 0.30 & Valid \\
Kinerja Karyawan & Instrumen No.6 & 0.537 & 0.30 & Valid \\
& Instrumen No.7 & 0.388 & 0.30 & Valid \\
& Instrumen No.8 & 0.461 & 0.30 & Valid \\
& Instrumen No.9 & 0.393 & 0.30 & Valid \\
& Instrumen No.10 & 0.310 & 0.30 & Valid \\
& Instrumen No.11 & 0.348 & 0.30 & Valid \\
& Instrumen No.12 & 0.416 & 0.30 & Valid \\
\hline
\end{tabular}

Sumber : Hasil Olah Data Penelitian

Uji Reliabilitas dapat dilihat pada tabel 2 di bawah ini

Tabel 2. Rekapitulasi Hasil Uji Reliabilitas

\begin{tabular}{lccc}
\hline \multicolumn{1}{c}{ Keterangan } & Koefisien Alpha $(\boldsymbol{\alpha})$ & Standar & Kesimpulan \\
\hline Kompetensi & 0.862 & 0.60 & Reliabel \\
Kompensasi & 0.745 & 0.60 & Reliabel \\
Kinerja Karyawan & 0.752 & 0.60 & Reliabel \\
\hline
\end{tabular}

Sumber : Hasil Olah Data Penelitian

\section{Analisis Hasil Penelitian}

\section{Pengaruh Kompetensi dan Kompensasi Terhadap Kinerja Karyawan}

Analisis regresi pada dasarnya adalah studi mengenai ketergantungan variabel dependen (kinerja) dengan variabel independen (kompetensi dan kompensasi) dengan tujuan untuk memprediksi perubahan nilai variabel terikat akibat pengaruh dari variabel bebas. 


\title{
Tabel 3. Pengaruh Kompetensi dan Kompensasi Terhadap Kinerja Karyawan
}

\begin{tabular}{|c|c|c|c|c|c|c|}
\hline \multirow[b]{2}{*}{$\begin{array}{c}\text { Hubungan } \\
\text { Variabel }\end{array}$} & \multicolumn{6}{|c|}{ Parameter } \\
\hline & $\begin{array}{c}\text { Mult. } \\
\text { R }\end{array}$ & $\begin{array}{c}\mathbf{R} \\
\text { Square }\end{array}$ & $\begin{array}{l}\text { Kons } \\
\text { tanta }\end{array}$ & Coef. B & Sig & $\boldsymbol{\alpha}$ \\
\hline $\begin{array}{l}\text { Kompetensi } \\
\text { Kompensasi }\end{array}$ & 0.838 & 0.701 & 9.987 & $\begin{array}{l}0.409 \\
0.832 \\
\end{array}$ & 0.000 & $5 \%$ \\
\hline \multicolumn{7}{|c|}{ Pengujian Signifikan } \\
\hline \multicolumn{7}{|c|}{ F hitung $>$ F Tabel $=111.586>3.092$} \\
\hline
\end{tabular}

\author{
a.Dependent Varibel : Kinerja \\ Sumber data dianalisis
}

Nilai F hitung $=111,586$ lebih besar dari F tabel 3,092 (111,586 > 3,092), artinya kompetensi dan kompensasi berpengaruh signifikan terhadap kinerja karyawan PT. Media Nusantara Citra, Tbk pada tingkat nyata $99 \%$

Koefisien determinasi yang diperoleh sebesar 0,701. Hal ini berarti 70,1\% kinerja karyawan dapat disumbangkan oleh kompetensi dan kompensasi, sedangkan sisanya sebesar 29,9\% disumbangkan oleh variabel lain yang tidak diteliti dalam penelitian ini.

Hasil penelitian menunjukkan model persamaan regresi linier sebagai berikut yaitu :

$$
\mathrm{Y}=9,987+0,409 \mathrm{X}_{1+} 0,832 \mathrm{X} 2+\mathrm{e}
$$

Berdasarkan persamaan regresi tersebut dapat dijelaskan bahwa kompetensi dan kompensasi berpengaruh positif terhadap kinerja karyawan. Hal ini dapat dilihat temuan koefisien penduga, dimana variabel kompetensi menghasilkan koefisien $(0,409)$ dan variabel kompensasi $(0,832)$ dengan masing-masing signifikansi $\alpha=0,05$ melalui penduga ini dapat digambarkan, bahwa kompetensi memberikan indikasi pengaruh yang relatif lebih rendah dari pada kompensasi. Pengaruh simultan tersebut, diprediksikan untuk penduga konstanta adalah positif sebesar 9,987, artinya secara simultan kedua variabel predictor tersebut memberikan dampak fluktuatif yang linier terhadap kinerja karyawan PT. Media Nusantara Citra, Tbk dengan tingkat signifikansi yang baik.

Koefisien regresi kompetensi sebesar 0.409 yang berarti jika ada perubahan 1 kali pada kompetensi, maka kinerja karyawan akan meningkat sebesar 0.409 satuan. Hal ini juga berlaku pada koefisien regresi kompensasi, yaitu sebesar 0.832 , yang berarti jika ada perubahan 1 kali pada kompensasi, maka kinerja karyawan akan meningkat sebesar 0.832 satuan.

Dari hasil pengolahan data tersebut telah berhasil dijawab permasalahan hipotesis yaitu ada pengaruh kompetensi dan kompensasi terhadap kinerja karyawan PT. Media Nusantara Citra, Tbk. Jadi kedua variabel yang diteliti, yaitu kompetensi dan kompensasi secara bersama-sama mempengaruhi kinerja karyawan PT. Media Nusantara Citra, Tbk

\section{KESIMPULAN DAN SARAN}

\section{Kesimpulan}

Berdasarkan hasil penelitian yang telah dilakukan dengan analisa pengaruh kompetensi dan kompensasi terhadap kinerja karyawan maka diperoleh kesimpulan sebagai berikut : 1). Terdapat pengaruh signifikan kompetensi terhadap kinerja karyawan, ini berarti semakin baik kompetensi, maka akan semakin meningkatkan kinerja

karyawan PT. Media Nusantara Citra TBK. 2) Terdapat pengaruh signifikan kompensasi terhadap kinerja karyawan PT. Media Nusantara Citra, Tbk, ini berarti 
semakin baik kompensasi kepada karyawan, maka akan semakin meningkatkan kinerja karyawan PT. Media Nusantara Citra Tbk.

\section{Saran}

Berdasarkan hasil penelitian maka perlu diberikan saran sebagai berikut : 1) Untuk memotivasi karyawan agar mampu berfikir dengan kritis supaya inovatif dan mempunyai gagasan baru yang berkembang di perusahaan maka perusahaan harus memberikan pelatihan dan pendidikan secara kontiniu untuk meningkatkan kompetensi karyawan. 2) Perusahaan perusahaan harus mampu menciptakan kultur kerja yang kondusif agar tercipta kerjasama tim yang solid supaya produktif. 3) Perusahaan harus bisa memberikan fasilitas kantor yang memadai untuk setiap karyawannya agar tercipta kenyamanan saat bekerja serta meningkatkan kinerja karyawan.

\section{DAFTAR PUSTAKA}

Abin Syamsuddin Makmun. 1999. Psikologi Pendidikan, Penerbit Andi,. Yogyakarta Jogiyanto, HM. 2009. Analisis dan Desain. Yogyakarta : Andi OFFSET.

Notoatmodjo, Soekidjo. 2009. Pengembangan Sumber Daya Manusia. Jakarta: Rineka Cipta

Riduwan. 2003. Skala Pengukuran variabel-variabel Penelitian. Bandung: Alfabeta.

Setiyawan, Budi dan Waridin. 2006. Pengaruh Disiplin Kerja Karyawan Dan Budaya Organisasi Terhadap Kinerja Di Divisi Radiologi RSUP Dokter Kariadi Semarang. JRBI. Vol 2. No 2. Hal: 181-198.

Sri Langgeng Ratnasari.2016. "Pengaruh Kompentensi dan Kompensasi terhadap Kinerja Karyawan PT. Media Nusantara Tbk”.

Sugiyono, 2007. Metodologi Penelitian Bisnis. PT. Gramedia, Jakarta

Sugiyono. 2005. Statistika Untuk Penelitian. Alfabeta. Bandung.

Winarno Surakhmad, 1990. "Pengantar Penelitian Ilmiah" : Dasar dan Teknik. Bandung: Tarsito 